Protestantismo em Revista é licenciada sob uma Licença Creative Commons.

http://dx.doi.org/10.22351/nepp.v45i1.3312

\title{
A TIPIFICAÇÃO IDEAL DA CORDIALIDADE: APORTES A PARTIR DO PENSAMENTO SOCIAL BRASILEIRO DE SÉRGIO BUARQUE DE HOLANDA
}

\author{
The ideal typification of cordiality: contributions [taking from the] Brazilian social thought \\ of Sergio Buarque de Holanda
}

Vagno Batista Ribeiro *

\begin{abstract}
Resumo?
A obra do historiador Sérgio Buarque de Holanda, Raízes do Brasil, constitui juntamente com Casa Grande \& Senzala, de Gilberto Freyre, as obras teóricas iniciais da interpretação do Brasil que deixaram de lado as teorias racialistas e passaram ao tema da cultura. Neste sentido, o presente artigo busca analisar alguns elementos acerca do conceito de Homem Cordial, apresentado no capítulo quinto de Raízes do Brasil, no sentido de elencar pontos da teorização do fazer historiográfico de seu autor. $O$ texto a seguir está organizado da seguinte maneira: breve reflexão acerca da tipificação ideal usada por Holanda, seguida de um apanhado a respeito do tema do desterro na elaboração teórica da cordialidade, concluindo por uma análise do personalismo como gosto pelo superficial.

Palavras-chave: Homem Cordial. Pensamento Social Brasileiro. Tipo Ideal. Desterro.

Abstract:

The work of the historian Sérgio Buarque de Holanda, Roots of Brazil, together with The Masters and the Slaves, by Gilberto Freyre, forms the initial theoretical works of the interpretation of Brazil that left aside the racialist theories and came to the theme of culture. In this sense, the present article seeks to analyze some elements about the concept of Cordial Man, presented in the fifth chapter of Roots of Brazil, in the sense of list some points of the historiographical theorization of its author. The following text is organized as follows: a brief reflection on the ideal typification used by Holanda, followed by a survey on the subject of exile in the theoretical elaboration of cordiality, concluding by an analysis of personalism as superficial taste.
\end{abstract}

Keywords: Cordial Man. Brazilian Social Thought. Ideal Type. Exile.

[Texto recebido em maio de 2018 e aceito em maio de 2018, com base na avaliação cega por pares realizada por pareceristas ad hoc]

* Mestre. UNISINOS. E-mail: profwagner2006@gmail.com.

Protestantismo em Revista | São Leopoldo | v. 45, n. 01 | p. 61-72| jan./jun. 2019

Disponível em: <http:// periodicos.est.edu.br/index.php/nepp> 


\section{Introdução}

O pensamento social brasileiro é formado por uma nuvem de autores relevantes e necessários ao entendimento das várias fases históricas pelas quais o país vem passando desde o final do século XIX quando se iniciaram as tentativas de interpretar o Brasil teoricamente. Raizes do Brasil, obra fundamental de Sérgio Buarque de Holanda, se insere nesta tradição e com boas razões desperta o interesse de muitos pesquisadores até os dias atuais.

A obra de Sérgio Buarque é moldada pela noção de desterro, pela noção de um não lugar, ou um lugar de fronteiras que faz surgir no espírito dos desterrados a noção de não pertencimento. É assim que Buarque de Holanda sentiu-se ao se demorar por mais tempo do que o devido na Alemanha quando era correspondente de um jornal brasileiro. É neste contexto da década de 1920 que ele redigirá em grande parte a sua obra fundamental, Raízes do Brasil, lançada três anos após Gilberto Freyre lançar Casa Grande \& Senzala, em 1933. A importância de Raízes para o debate a respeito da identidade nacional é muito importante e ainda relevante. Nesta obra, Buarque de Holanda trata do desterro do colono ibérico e da impessoalidade, ausente no trato rural, como elementos conjugadores da problemática teórica tratada por ele, a saber, a cordialidade como característica do indivíduo imerso na lógica rural e na prática do personalismo. E é no sentido desta exposição que o presente artigo intenta apresentar alguns elementos do fazer historiográfico próprios de Buarque de Holanda.

\section{Historiografia e tipificação ideal em Sergio Buarque de Holanda}

A obra Raízes do Brasil é um produto do desterro. ${ }^{1}$ Sérgio Buarque de Holanda redigiu grande parte de seu projeto quando estava na Alemanha para cobrir jornalisticamente os acontecimentos que lá se descortinavam. Neste contexto ele pôde testemunhar os processos que mais tarde ficaram conhecidos no Brasil a respeito do nascente nacional-socialismo que elevou Hitler ao poder. Também foi lá que Sérgio Buarque de Holanda teve contato com a obra do sociólogo alemão Max Weber. A obra Raízes do Brasil é uma obra que caracteriza uma experiência de olhar o Brasil de maneira estrangeira, isto é, desde o lado de fora e a partir de um referencial teórico não construído no caldo cultural país. O livro que é um dos clássicos que buscam interpretar o Brasil na primeira metade do século XIX, foi publicado em 1936. Sérgio Buarque era o correspondente de um jornal brasileiro na Alemanha, local em que ele já havia redigido uma obra de 400 páginas e que se perdeu. Em Raízes do Brasil, há uma teoria a respeito da condição, da origem e continuidade acerca da nacionalidade brasileira. $\mathrm{O}$ autor busca traduzir numa teoria geral baseada em pontos comuns aos processos de construção teórica, a respeito das próprias nacionalidades europeias, um jeito próprio de explicar a maneira pela qual as fronteiras

1 DECCA, Edgar Salvadori de. Ensaios de nacionalidade: cordialidade, cidadania e desterro na obra de Sérgio Buarque de Holanda. Locus: revista de história, Juiz de Fora, v. 12, n. 1, p. 145-159, 2006. Disponível em: <http://www.ufff.br/locus/files/2010/02/82.pdf>. Acesso em: 2 abr. 2018. 
teriam influenciando o jeito de ser do povo brasileiro. O tema "desterro" aparece em várias obras de Sérgio Buarque de Holanda como em Monções, Caminhos e Fronteiras e Extremooeste. Estas obras falam das relações de desterro que surgem dentro do próprio terreno e geografia do Brasil com a mudança de parte da população ibérica e lusa para o continente americano. As viagens historiográficas que o autor faz buscam falar da identidade ou da falta dela. "O livro é construído por um sistema de oposições que durante todo o tempo relaciona a cultura ibérica nas suas dimensões lusitanas e espanholas" . ${ }^{2}$ Extremo Oeste aborda as questões das fronteiras mais longínquas, enquanto Caminhos e Fronteiras passa a ideia de movimento do passageiro em lugares que encaminha a determinados limites. Nestas obras, o autor faz uma importante interiorização da experiência do desterro. Mais tarde, Sérgio Buarque de Holanda apresenta a obra Visão do Paraíso, ${ }^{3}$ de 1958, abordando essa perspectiva do homem que emigrou ao Brasil e aqui se sente um estrangeiro inconteste.

Os temas da fronteira, do movimento e do desterro aparecem com frequência na obra de Sérgio Buarque. O autor procura caracterizar a maneira pela qual o estrangeiro via a América e como ele a idealizava desde a Europa. Para ele, o ibérico e o luso se constituíam num espírito aventureiro, num ser em movimento, num projeto de enriquecimento rápido, não dado à estabilidade e à colonização racional da geografia. E na contramão dessa tendência histórica, a cidadania como característica da urbanidade requeria a estabilidade na geração da múltipla identidade. A noção tornada comum por Antônio Cândido, a de que haveria desde Silvio Romero um grupo de intérpretes do Brasil, tem na obra Raízes do Brasil um de seus célebres textos fundadores da explicação da nacionalidade. ${ }^{4}$

Explicitando as ideias responsáveis pela clivagem presente nas obras de Gilberto Freyre, de Sérgio Buarque de Holanda e de Caio Prado Jr., Antônio Candido chama a atenção para a particularidade desses autores no tratamento de nossos problemas, inscrita em dicções intelectuais incomuns no passado. A despeito da diversidade que os individualiza, encarnaram a face mais renovadora do pensamento oriundo dos anos de 1930 e que marcará a cultura brasileira em toda a sua trajetória ulterior. ${ }^{5}$

Estes autores são tomados como redescobridores do Brasil. Podem ser citados como Intérpretes do Brasil, Sergio Buarque de Holanda, Gilberto Freyre, Caio Prado Júnior, Oliveira Viana, etc. Estes autores fizeram uso de teorias sociológicas e da história para explicar situações muito específicas do contexto latino-americano, especificamente a respeito daquilo que ficou conhecido como caráter nacional do brasileiro. Eles se colocaram na contramão das teorias e dos conceitos racialistas que eram dominantes até o início do século XX.

2 DECCA, 2006.

3 HOLANDA, Sérgio Buarque de. Visão do paraíso: os motivos edênicos no descobrimento e colonização do Brasil. 5. ed. São Paulo: Brasiliense, 1992.

4 ARRUDA, Maria Arminda do Nascimento. Pensamento brasileiro e sociologia da cultura questões de interpretação. Tempo Social - USP, junho, p. 107-118, 2004. Disponível em:

<http://www.scielo.br/pdf/ts/v16n1/v16n1a06.pdf>. Acesso em: 20 abr. 2018.

5 ARRUDA, 2004, p. 107. 
Sem dúvida, essa distinção é importante, pois retirou o substrato de uma ideologia racial que caracterizava as interpretações do ser nacional. Esse modelo de interpretação do Brasil, baseado em caracteres raciais, não era novo, tampouco era também a preocupação de se definir "quem somos nós". Essa questão de "quem somos" foi levantada no século XIX, com a consolidação do Estado Nacional no Brasil, e permaneceu como nossa indagação mais urgente, tornando-se, a partir dessa época, uma verdadeira obsessão da intelectualidade no Brasil. Evidentemente, a questão tem uma conotação absolutamente política, por que ao definir "quem somos", definimos também os agentes legitimamente reconhecidos para a ação política. Não é por acaso que essa questão tenha sido formulada na inauguração do Estado Nacional Brasileiro e tenha se tornado a indagação maior de toda a tradição intelectual do Brasil. Dessa indagação política do ser nacional, projetam-se todos os modelos políticos da intelectualidade brasileira, desde o século XIX. ${ }^{6}$

Sérgio Buarque criou uma organização tipológica a respeito de uma possível característica do ser nacional, que foi muito original e controversa, gerando muito debate que ainda hoje é atacada como adaptação forçada de uma teoria a respeito do patrimonialismo de Weber ao contexto latino-americano. ${ }^{7} \mathrm{Na}$ concepção de Weber, o tipo ideal seria um instrumento da análise sociológica construído com o objetivo de apreender os fenômenos sociais, sendo um de seus principais caracteres o fato de que o tipo ideal não corresponderia necessariamente à realidade, mas ajudaria na compreensão dos processos sociológicos e históricos a respeito de fenômenos sociais. O tipo ideal como método de análise é estabelecido de forma racional, sem, com isso, ignorar as bases de escolhas pessoais anteriores daquele que analisa o fenômeno. Não está desvinculada a subjetividade do pesquisador do processo de compreensão do fenômeno histórico ou sociológico em questão, mas reconhecida como elemento pertencente aos seus pressupostos teóricos. ${ }^{8}$ Trata-se, então, de um conceito teórico abstrato criado com base na realidade-indução. É um guia que serve na análise da variedade de fenômenos que ocorrem no mundo da realidade. É um conceito lógico e não contraditório, que é construído desde a abstração de uma relação da realidade. $\mathrm{O}$ tipo ideal tem como escopo a generalização desde uma referência que busca compreender aproximadamente uma dada realidade. É um conceito epistêmico distinto baseado na diferenciação trazida por Dilthey ${ }^{9}$ a respeito das especificidades de cada campo do conhecimento das humanidades e das ciências naturais. Compreender, no campo das ciências humanas, seria aproximar-se hermeneuticamente dos fenômenos, enquanto explicar, no campo das ciências naturais, seria um processo de redução epistêmica sobre um dado objetivo. Tipo ideias seriam esquemas mentais construídos pelo pesquisador no

6 DECCA, Edgar Salvadori de. Cordialidade, cidadania e Desterro na obra de Sérgio Buarque de Holanda. p. 77-103. In: SCHULER Fernando Luis; DECCA, Edgar de. Intérpretes do Brasil: homenagem a Sérgio Buarque de Holanda. Porto Alegre: 2005. p. 82-83.

7 Conferir SOUZA, Jessé. A Tolice da Inteligência Brasileira: ou como o país se deixa manipular pela elite. São Paulo: Leya, 2015. Neste livro, o autor busca desconstruir a tese de Sérgio Buarque dizendo que o autor força a interpretação acerca do patrimonialismo português como sobrevivente nas instituições brasileiras. p. 39-50.

8 JASPERS, Karl. Introdução ao pensamento filosófico. São Paulo, SP: Cultrix, [19--]. p. 75-84.

9 FRANCO, Sérgio de Gouvêa. "Dilthey: compreensão e explicação" e possíveis implicações para o método clínico. Rev. latinoam. psicopatol. fundam. v. 15, n.1, São Paulo, mar, 2012. Disponível em: <http://www.scielo.br/scielo.php?script=sci_arttext\&pid=S1415-47142012000100002 >. Acesso em: 15 abr. 2018. 
intuito de definir certos objetos de investigação. Ideal aqui se refere simplesmente à ideia, ao pensamento abstrato.

É importante notar que Max Weber classifica os tipos ideais em três espécies, quais sejam, i) tipos ideais de conjunções históricas, por exemplo: a sociedade capitalista, a urbanidade do Ocidente, o feudalismo, entre outros. Aqui, a tipificação ideal se constitui numa reconstrução de uma determinada realidade, ou de um fato histórico mais amplo, porém específico, ainda que amplo ou mesmo global, uma vez que se trataria de um regime econômico (capitalismo) muito abrangente, de um tipo de organização social (cidade), ou de uma forma ajuntamento humano (feudalismo). De todo modo, específico, pois Weber reconstruía um tipo único quando analisava um determinado fenômeno; ii) tipos ideais de conjunções abstratas da realidade histórica, que, no entanto, podem ser encontradas em várias situações. Nesta categoria estariam, por exemplo, a burocracia (dominação), que por seu caráter abstrato apareceria em diversos períodos históricos, inclusive no capitalismo. Esta forma de tipificação ideal, construída em um nível mais abstrato, poderia ainda ser dividida em três tipos de burocracia: a racional, fundada em leis e regulamentos; a tradicional, organizada a partir da tradição e do costume; e a carismática, pautada pelo "carisma" ou pela virtude de um líder; iii) tipos ideias de conjunções fundada na reformulação teórica, reconstrução racionalizante de uma forma específica de condutas e de comportamento. Para Weber, por exemplo, proposições da teoria econômica não passariam de uma idealização do comportamento dos agentes econômicos, ou seja, dos indivíduos. Weber lista como exemplo desta tipificação ideal, o comportamento do burguês do período mercantilista na Holanda do século XVIII. ${ }^{10}$

É a partir de uma tipificação ideal que Sérgio Buarque buscará compreender o tema da identidade latente na sua época. A identidade nacional havia sido assunto de muitos autores brasileiros como Sílvio Romero, Nina Rodrigues, Euclides da Cunha, João Batista Lacerda, Manuel Bonfim, Manuel Quirino, Joaquim Nabuco, etc. Nesse sentido, há uma ação política sob a escrita de Sérgio Buarque, assim como de todos os autores modernistas ou, antes deles, dos parnasianos, ou dos românticos, entre outros. Havia uma certa ideia no ar a respeito das potencialidades ontológicas do povo brasileiro. A dificuldade, no entanto, estava em responder "quem somos".

Não são poucos os intelectuais latino-americanos que remetem à ação política e
também a condicionam numa ontologia do ser nacional. Isto porque, para a maioria
dos intérpretes da nacionalidade, o que somos é sempre a projeção de um outro, isto
é, do dominador estrangeiro europeu. Sérgio Buarque procura encontrar uma
resposta para esse enigma identitário e que de certa forma torna-se um obstáculo
para a ação política no presente. Apesar de ter escrito Raízes do Brasil na década de
trinta do século 20, ele entra num debate que já havia se instalado entre a
intelectualidade latino-americana a partir, pelo menos, do período do modernismo.
Há outras obras emblemáticas sobre a questão da nacionalidade no continente

10 WEBER, Max. Coleção Os Pensadores. São Paulo. Abril Cultural: 1980. p. 14-15. 
americano, destacando-se entre elas, pelo menos, Os sertões de Euclides da Cunha, Facundo de Domingo Sarmiento e também Ariel de Jose Enrique Rodó [...].11

É também - e finalmente - de Sérgio Buarque de Holanda o alerta, encontrado no capítulo quinto de Raízes do Brasil, a problemática do homem cordial, do indivíduo apegado irrestritamente aos "valores da personalidade" acima de qualquer coisa, aos valores das relações pessoais em detrimento de um mal compreendido liberalismo que seria, na verdade, um "mal-entendido" aspecto da sociedade moderna por que pautada na impessoalidade das regras sociais do direito, uma aberração ao contexto da Casa Grande e da Senzala. É no capítulo a respeito do homem cordial, esse ser que odeia as relações mais objetivas e burocráticas de impessoalidade, que Sérgio Buarque fez sucesso e, mais ardentemente, foi e é combatido.

\section{O desterro como tema historiográfico}

As dificuldades entre a vida pública e a vida privada são tematizadas na obra de Sérgio Buarque. Para Holanda, superar essa confusão tem a ver com a resposta à pergunta "quem somos". Para ele, é importante compreender que a confusão se faz presente na própria maneira de se entender o dilema do assim chamado Homem Cordial, um indivíduo preso entre as fronteiras. Essa instabilidade própria do ruralismo ibérico, e mantido nos trópicos, impede que o caráter nacional passe aos novos modos da modernidade tão bem caracterizada por Weber em sua narrativa a respeito da sociedade capitalista como impessoal e racionalista.

O tema das fronteiras aparece sempre com força na organização do indivíduo nacional como ser social desterrado, aquele que não consegue fazer essa distinção entre sua vida pública e sua vida privada, característica fundamental da noção de cordialidade brasileira, que Sérgio Buarque de Holanda tomou do escritor Ribeiro Couto.12 Para Sérgio Buarque essa ideia não significa bondade, mas o privilégio de questões privadas sobre as públicas. Melhor dizendo, significa antes a noção do privilégio de questões do coração, das questões íntimas, sobre o âmbito público. "Sérgio Buarque de Holanda nos apresenta o 'Homem Cordial' como traço do caráter brasileiro. O brasileiro seria então aquele que: reage através das relações afetivas, tem horror às distâncias", ${ }^{13}$ busca incessantemente tornar toda a impessoalidade em relações pessoais, quebrando o aspecto cerimonioso, objetiva estabelecer relações ao nível da intimidade. É arredio a ordens ou normas e leis coletivas. Em seu sentido:

11 DECCA, 2005, p. 150-151.

12 HOLANDA, Sérgio Buarque de. Raízes do Brasil. São Paulo: Companhia das Letras, 1995. p. 146.

13 MARÇOLA, Fernanda Gonçalves. O que é cordialidade?: o conceito de cordialidade em Sérgio Buarque de Holanda e Gilberto Freyre. Monografia (Estágio Supervisionado em Pesquisa Histórica) - Curso de Graduação em História, no Setor de Ciências Humanas da Universidade Federal do Paraná, Curitiba, 2005. Disponível em:

<http://www.humanas.ufpr.br/portal/historia/files/2013/03/fernanda_goncalves_marcola.pdf>. Acesso em: 16 abr. 2018. 
[...] estritamente etimológico, se não tivesse sido contrariamente interpretada em obra recente de autoria do Sr. Cassiano Ricardo onde se fala no homem cordial dos aperitivos e das "cordiais saudações", "que são fechos de cartas tanto amáveis como agressivas" e se antepõe à cordialidade assim entendida o "capital sentimento" dos brasileiros (...) feito este esclarecimento e para melhor frisar a diferença, em verdade fundamental, entre as ideias sustentadas na referida obra e as sugestões que propõe o presente trabalho, cabe dizer que, pela expressão "cordialidade", se eliminam aqui, deliberadamente, os juízos éticos e as intenções apologéticas a que parece inclinarse o Sr. Cassiano Ricardo, quando prefere falar em "bondade" ou em "homem bom". Cumpre ainda acrescentar que essa cordialidade, estranha, por um lado, a todo formalismo convencionalismo social, não abrange, por outro lado apenas e obrigatoriamente, sentimentos positivos e de concórdia. A inimizade bem pode ser tão cordial como a amizade, nisto que uma e outra nascem do coração, procedem assim, da esfera do íntimo, do familiar, do privado [...].14

Sérgio Buarque afirma que a ideia do homem cordial é atribuída ao povo brasileiro como contribuição à civilização. Ele tenta cavar na história da formação social dos brasileiros a essência de um ser social que, segundo ele, está desterrado em sua própria vivenda. É importante esclarecer que não se trata de uma análise do caráter psicológico compreendido como algo fixo e imóvel, algo que fosse essencial e sem história. Quando dizemos essência queremos nos referir àquilo que o caracteriza historicamente. Pelo contrário, embora exista a tentativa de elencar algumas características da psicologia do homem cordial, Buarque de Holanda busca conferir a este ser social o resultado da produção e da formação histórica e contextual do homem brasileiro, considerando, para tanto, a perspectiva do desterro, como um atavismo herdado de Portugal que sobreviveria ainda à miscigenação com os elementos africanos e indígenas. Nesse sentido, o homem cordial seria assim um produto histórico que se encontraria vinculado ao passado e preso à própria corrente da história. Este ser social estaria sob um trauma profundo por estar num lugar nenhum, por estar numa periferia sem centro, por estar, portanto, num não lugar que o deixaria num limite de sobrevivência e necessidade de superação das questões herdadas, uma importante perspectiva de avanço na história. Segundo nosso weberiano intérprete do Brasil, o homem cordial se caracterizaria como um ser psicológico completamente arredio ao processo civilizatório caracterizado pela impessoalidade, pelas regras de formalidade e de convenção. Segundo ele,

A lhaneza no trato, a hospitalidade, a generosidade, virtudes tão gabadas por estrangeiros que nos visitam, representam, com efeito, um traço definido do caráter brasileiro, na medida, ao menos, em que permanece ativa e fecunda a influência ancestral dos padrões de convívio humano, informados no meio rural e patriarcal. Seria engano supor que essas virtudes possam significar "boas maneiras", civilidade. São antes de tudo expressões legítimas de um fundo emotivo extremamente rico e transbordante. Na civilidade há qualquer coisa de coercitivo ela pode exprimir-se em mandamentos e em sentenças. Entre os japoneses, onde, como se sabe, a polidez envolve os aspectos mais ordinários do convívio social, chega a ponto de confundir-se, por vezes, com a reverência religiosa. Já houve quem notasse este fato significativo, de que as formas exteriores de veneração à divindade,

14 HOLANDA, Sérgio Buarque de. Raízes do Brasil. 3. ed. Rio de Janeiro: José Olympio, 1956. p.136-7. 
no cerimonial xintoísta, não diferem essencialmente das maneiras sociais de demonstrar respeito. ${ }^{15}$

Segundo Buarque de Holanda, o homem cordial viveria em sociedade como um subterfúgio ao horror de viver consigo mesmo. Para ele, a vida em sociedade seria de certa maneira uma libertação porque ele ressentir-se-ia em viver consigo mesmo, em apoiar-se sobre si e sobre suas capacidades pessoais em todas as situações da existência.

No "homem cordial", a vida em sociedade é, de certo modo, uma verdadeira libertação do pavor que ele sente em viver consigo mesmo, em apoiar-se sobre si próprio em todas as circunstâncias da existência. Sua maneira de expansão para com os outros reduz o indivíduo, cada vez mais, à parcela social, periférica, que no brasileiro - como bom americano - tende a ser a que mais importa. Ela é antes um viver nos outros. Foi a esse tipo humano que se dirigiu Nietzsche, quando disse: "Vosso mau amor de vós mesmos vos faz do isolamento um cativeiro". ${ }^{16}$

Não se trata de ser a cordialidade uma característica da bondade do brasileiro. A cordialidade não é uma questão simples de concórdia e de sentimentos positivos, a inimizade também é um atributo de sua constituição, ambas são geradas do ambiente íntimo, familiar, privado, não na esfera pública. Nesta, a cooperação racional poderia estar implicada. Para Sérgio Buarque de Holanda, se caracterizaria a cordialidade também como hostilidade social. ${ }^{17}$ A cordialidade estaria assim na contramão da racionalidade abstrata.

Desta forma, "Raízes do Brasil tem páginas inteiras inspiradas em Weber. A sua discussão do Estado brasileiro, das relações entre o público e o privado, a sua proposta de uma separação radical entre estas esferas e da modernização do Estado [...] os tipos ideais do trabalhador e do aventureiro, do ladrilhador e do semeador, do homem cordial e do homem polido, a análise comparativa da mentalidade ibérica e da europeia, das mentalidades portuguesa e espanhola na América e os conceitos de dominação patrimonial e burocrático..." 12 É a partir de Weber que Sérgio Buarque cria a tipologia dos pares contrários que perpassam o tecido social do Brasil desde a colônia até o século XX.18

O homem cordial - o semeador luso - estaria em oposição ao ladrilhador - o geômetra hispânico. A cidade construída pelo modelo português não seria um produto mental, isto é, um produto da elaboração racional e da empreita projetada no cálculo abstrato, mas uma adaptação ao quadro da natureza. Enquanto os portugueses estariam entregues ao desleixo, ${ }^{19}$ que "implica menos a falta de energia do que a íntima convicção de que não vale a pena", 20 os espanhóis se superariam na retificação da paisagem agreste. $\mathrm{O}$ que Buarque de Holanda deseja é explicar por meio de uma teoria a respeito da América a

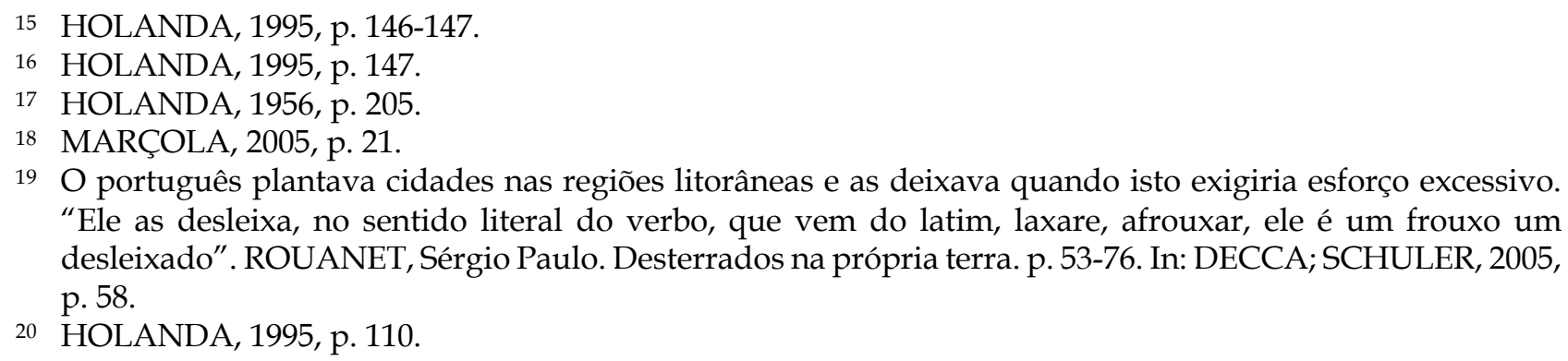


ocupação europeia dos trópicos. Para ele, o que se constituiu no Brasil foi "uma tentativa bem sucedida, e em larga escala, de transplantação da cultura europeia para uma zona de clima tropical" ${ }^{21}$ Essa parece ser a ideia que rege a organização do texto fundamental de Buarque de Holanda, qual seja, a percepção histórica da formação da sociedade brasileira como uma transplantação de uma sociedade europeia para o contexto dos trópicos em contraste a outras sociedades latino-americanas. Daí ser o tema do desterro tão importante no pensamento do historiador.

\section{Personalismo ibérico como gosto pelo superficial}

Dentre o atavismo ibérico característico do personalismo cordial, conforme destaca Sérgio Buarque, estaria a tendência em antepor o prestígio e projeto pessoal às considerações do bem comum. Uma outra característica é a capacidade de aventura tão marcante nos ibéricos, o que permitiria ganhos rápidos em contraposição a outros povos organizados desde uma ética do trabalho no qual predominaria o esforço sistemático por adquirir a poupança. Haveria ainda como traço ibérico herdado pelo homem cordial o predomínio do ruralismo, o domínio da fazenda sobre o elemento urbano, a ênfase nos valores rurais em detrimento da cidade. O ruralismo atávico seria a permanência de preocupações aristocráticas. Esse seria a origem do gosto pelo brilho, pela ostentação e distinção social. O homem cordial estaria preocupado em alardear riqueza e supremacia intelectiva, apenas. É, neste contexto, que surge o gosto pelo bacharelismo e sua ênfase nos diplomas, na valorização da habilidade técnica, conhecimento livresco e, principalmente, sua flutuação e instabilidade nas escolhas e opções políticas. Em suma, o homem cordial seria adepto de modismos intelectuais, uma vez que esse gosto tão flutuante corresponderia ao modo de ser rural no qual importa mais parecer do que ser.

A noção de homem cordial, ao que tudo parece, está ligada à tradição portuguesa e pode ser interpretada a partir da palavra cordis, que é coração em latim. Nesse sentido, a cordialidade deve ser interpretada etimologicamente como algo dado às emoções, isto é, tanto à simpatia e ao amor quanto à hostilidade e ao ódio. Não tem nada a ver com a ideia de polidez ou civilidade. Aliás, a palavra polidez vem de Polis, e a palavra civilidade de Civitas, ambas noções alheias ao contexto da ruralidade Ibérica. Isso significa que polidez e civilidade deveriam ser regras que o homem ibérico conseguisse seguir de maneira abstrata. No entanto, o homem cordial não é polido e nem cheio de civilidade, mas sim criado por um único e fundamental critério, a saber, o personalismo que constrói relações de interesse afetivo e social pautado simplesmente pelo interesse próprio e local, a realidade da fazenda, o ethos específico do ruralismo ibérico.

A mentalidade do brasileiro formado no meio rural estaria caracterizada por heranças ibéricas e lusas que a impediria de compreender e se abrir a um interesse coletivo;

21 PESAVENTO, Sandra Jatahy. Cartografias do Tempo: palimpsestos na escrita da história. p. 17-88. In: PESAVENTO, Sandra Jatahy (Org.). Um historiador nas fronteiras: o Brasil de Sérgio Buarque de Holanda. Belo Horizonte: UFMG, 2005. p. 53 
também o aventureirismo a levaria a odiar o esforço e o trabalho racional e metódico, pois a mentalidade rural estaria constituída e pautada na rotinização e desvalorização do trabalho manual. A ostentação do saber superficial, livresco e bacharel, submeteria o homem cordial à incapacidade de construir projetos de inter pessoalidade calcados na racionalidade impessoal, visando o bem-estar do grupo social ou mesmo da nação. Estas características serviram de percepção metodológica a respeito da história do ser social brasileiro. Ao ser social estaria vinculada a herança Ibérica que mobilizaria o comportamento e hábitos mentais dos brasileiros à reticência quanto aos hábitos e comportamentos próprios à modernidade econômica, política e cultural.

\begin{abstract}
Sérgio Buarque de Holanda escreve Raízes do Brasil em um claro momento de transição da história brasileira, quase anunciando o Estado desenvolvimentista de Getúlio Vargas, quando então dois temas eram constantemente acionados: a questão rural e o problema da tradição. E aí reside a originalidade da obra. No lugar de uma história das positividades, ao contrário do uso de um modelo racial ou mesmo exclusivamente cultural, Holanda propõe, à semelhança dos "tipos ideais" usados por Max Weber, a introdução de dicotomias e tipologias - quase tipos polares - que ajudariam na explicação dos extremos da sociedade brasileira. ${ }^{22}$
\end{abstract}

À pergunta "quem somos", Buarque de Holanda postulou a superação do homem cordial para que o Brasil pudesse de fato assumir sua posição como povo e consequentemente como nação que tivesse o seu próprio espírito. A superação do personalismo, a valorização de uma ética do trabalho e da urbanidade seriam os remédios cívicos contra o atavismo ibérico. Nesse sentido, fazer historiografia a partir da contribuição desse grande intérprete do Brasil, que é Sérgio Buarque de Holanda, implica em compreender por meio de sua tipificação ideal que a valorização dos elementos cotidianos que, segundo ele, deveriam caracterizar o americanismo, é uma forma política de entender a construção do ser social do Brasil.

\title{
Considerações Finais
}

A ideia de cordialidade presente na teoria historiográfica de Sérgio Buarque de Holanda ajuda a perceber a relação profícua entre a pesquisa do cotidiano e os elementos de herança que se conjugam ao longo dos processos históricos. O homem cordial, discutido na obra Raízes do Brasil, está emoldurado dentro de um esquema metodológico dos tipos ideais de Max Weber, e busca traçar um parâmetro de compreensão a respeito de práticas sociais que teriam sido herdadas do elemento ibérico. Não se trata de um traçado explicativo das características da personalidade psicológica do brasileiro, mas uma aproximação compreensiva de uma totalidade bem específica, o ser social ataviado à realidade rural do Brasil. De acordo com essa teorização, haveria um entrave muito específico ao desenvolvimento do Brasil que se justificaria pela permanência dos elementos ibéricos e

22 SCHWARCZ, Lilia Moritz. Sérgio Buarque de Holanda e essa tal de "cordialidade". Psicanálise e cultura, São Paulo, 31(46), p. 83-89, 2008. p. 86. Disponível em: <http:// pepsic.bvsalud.org/pdf/ide/v31n46/v31n46a15.pdf>. Acesso em: 16 abr. 2018. 
lusos, em grande medida, sobreviventes no jeito de ser dos indivíduos. Esse jeito de ser seria marcado pela cordialidade, pelo aventureirismo e pelo desleixo tão característicos da tradição trazida ao Brasil pelos colonos portugueses, ou seja, um tipo de ojeriza à impessoalidade que marcaria profundamente o modo de praticar a sociabilidade dos brasileiros, um certo horror à introspecção e ao exercício da racionalidade, tão próprios à modernidade e suas exigências.

Como vimos, a cordialidade estaria na contramão do desenvolvimento moderno, pois, segundo Holanda, que assume a teoria weberiana dos tipos ideais, a falta de uma tradição própria ao Brasil - devido ao fator desterro - implicaria em uma diminuta presença de processos impessoais, sendo o apego ao ruralismo uma tendência dos brasileiros prejudicial aos desafios da nação. Para o intérprete do Brasil, a impessoalidade do modo de organização capitalista não se fazia presente no seio da sociedade brasileira, e isso era um problema que gerava o atraso do país. O homem cordial, levado pelas emoções, pois pautado pelas relações de proximidade à lógica da fazenda, não estava fundado na pura ideia de uma consequência de boas relações sociais, a cordialidade podia implicar em hostilidades devido ao fato de estar baseada no personalismo, o que significa ser guiado pelos interesses próprios acima de qualquer coisa.

Nesse sentido, o homem cordial como tipo ideal anda pode ajudar a compreender aproximadamente alguns fenômenos da sociedade brasileira. Se se pode dizer com certa segurança que ainda a sociedade brasileira não aprendeu a ser guiada por critérios impessoais no quesito separação entre o público e privado, se ainda presenciamos a confusão entre estas esferas, talvez poderíamos dizer que a cordialidade ainda é presente e, portanto, Raízes do Brasil é uma obra historiográfica importante na construção de uma interpretação das características do jeito brasileiro em lidar com o público e o privado.

\section{Referências}

ARRUDA, Maria Arminda do Nascimento. Pensamento brasileiro e sociologia da cultura questões de interpretação. Tempo Social - USP, junho, p. 107-118, 2004. Disponível em: <http://www.scielo.br/pdf/ts/v16n1/v16n1a06.pdf>. Acesso em: 20 abr. 2018.

DECCA, Edgar Salvadori de. Cordialidade, cidadania e Desterro na obra de Sérgio Buarque de Holanda. p. 77-103. In: SCHULER Fernando Luis; DECCA, Edgar de. Intérpretes do Brasil: homenagem a Sérgio Buarque de Holanda. Porto Alegre: 2005.

Ensaios de nacionalidade: cordialidade, cidadania e desterro na obra de Sérgio Buarque de Holanda. Locus: revista de história, Juiz de Fora, v. 12, n. 1, p. 145-159, 2006. Disponível em: <http://www.ufjf.br/locus/files/2010/02/82.pdf>. Acesso em: 2 abr. 2018.

FRANCO, Sérgio de Gouvêa. "Dilthey: compreensão e explicação" e possíveis implicações para o método clínico. Rev. latinoam. psicopatol. fundam. v. 15, n.1, São Paulo, mar, 2012. 
Disponível em: $\quad<$ http://www.scielo.br/scielo.php?script=sci_arttext\&pid=S141547142012000100002>. Acesso em: 15 abr. 2018.

HOLANDA, Sérgio Buarque de. Raízes do Brasil. 3. ed. Rio de Janeiro: José Olympio, 1956. . Raizes do Brasil. São Paulo: Companhia das Letras, 1995. . Visão do paraíso: os motivos edênicos no descobrimento e colonização do Brasil. 5. ed. São Paulo: Brasiliense, 1992.

JASPERS, Karl. Introdução ao pensamento filosófico. São Paulo, SP: Cultrix, [1990].

MARÇOLA, Fernanda Gonçalves. O que é cordialidade?: o conceito de cordialidade em Sérgio Buarque de Holanda e Gilberto Freyre. Monografia (Estágio Supervisionado em Pesquisa Histórica) - Curso de Graduação em História, no Setor de Ciências Humanas da Universidade Federal do Paraná, Curitiba, 2005. Disponível em: <http://www.humanas.ufpr.br/portal/historia/files/2013/03/fernanda_goncalves_mar cola.pdf>. Acesso em: 16 abr. 2018.

PESAVENTO, Sandra Jatahy. Cartografias do Tempo: palimpsestos na escrita da história. p. 17-88. In: PESAVENTO, Sandra Jatahy (Org.). Um historiador nas fronteiras: o Brasil de Sérgio Buarque de Holanda. Belo Horizonte: UFMG, 2005.

SCHWARCZ, Lilia Moritz. Sérgio Buarque de Holanda e essa tal de "cordialidade". Psicanálise e cultura, São Paulo, 31(46), p. 83-89, 2008. p. 86. Disponível em: <http:/ / pepsic.bvsalud.org/pdf/ide/v31n46/v31n46a15.pdf>. Acesso em: 16 abr. 2018.

SOUZA, Jessé. A Tolice da Inteligência Brasileira: ou como o país se deixa manipular pela elite. São Paulo: Leya, 2015.

WEBER, Max. Coleção Os Pensadores. São Paulo. Abril Cultural: 1980. 